\title{
Significance of the Epithelial Collar on the Subepithelial Connective Tissue Graft
}

Ho-Young Byun, ${ }^{*}$ Tae-Ju Oh, ${ }^{\dagger}$ Heba M. Abuhussein, ${ }^{\dagger}$ Junro Yamashita, ${ }^{\dagger}$ Stephen E. Soehren, ${ }^{\dagger}$ and Hom-Lay Wang ${ }^{\dagger}$

Background: Most clinicians adopt two versions of the subepithelial connective tissue graft (SCTG) procedure, SCTG with or without the epithelial collar on the graft combined with a coronally advanced flap (CAF). However, limited evidence is available to determine whether a retained epithelial collar on an SCTG is needed for a better outcome. The goal of this study was to compare the clinical outcomes of the two SCTG techniques (i.e., SCTG with or without an epithelial collar).

Methods: Twenty patients with Miller Class I or II gingival defects $\geq 2.0 \mathrm{~mm}$ were recruited for the study. The patients were randomly assigned to receive an SCTG with a retained epithelial collar + CAF (SCTGE; $n=10$ ) or an SCTG without an epithelial collar + CAF (SCTGN; $n=10)$. Clinical parameters, including recession depth, recession width (RW), width of keratinized gingiva (KW), clinical attachment level (CAL), probing depth (PD), gingival index (GI), and plaque index (PI), were assessed at baseline and 3 and 6 months after surgery.

Results: SCTGE and SCTGN groups exhibited significant root coverage at 3 and 6 months compared to baseline $(P<0.05)$. The SCTGE group had mean root coverage of $97.50 \% \pm 7.90 \%$ at 6 months compared to $89.10 \% \pm 25.93 \%$ in the SCTGN group, with no significant difference between the groups. At 6 months, complete root coverage was seen in nine of 10 and seven of 10 subjects from SCTGE and SCTGN groups, respectively. Mean KW at 3 months for the SCTGE group was $4.10 \pm 1.10 \mathrm{~mm}$, whereas in the SCTGN group it was $2.75 \pm 0.68 \mathrm{~mm}$. Mean RW was $0 \mathrm{~mm}$ and $1.20 \pm 1.60 \mathrm{~mm}$ for SCTGE and SCTGN groups, respectively. KW and RW were statistically significantly different between the two groups at 3 months; however, this significance was not seen at 6 months. Other clinical parameters (CAL, PD, thickness of the recipient gingival tissue, PI, GI, and the wound healing index) showed no significant differences between the groups at any time point.

Conclusions: Both SCTG techniques (with or without the epithelial collar) provided predictable and successful root coverage ( $\geq 89 \%)$. This study suggests that a retained epithelial collar on the SCTG may not provide a significant benefit with regard to clinical parameters. J Periodontol 2009;80:924-932.

\section{KEY WORDS}

Connective tissue; gingival recession; graft.

\footnotetext{
* Currently, private practice, Seoul, Korea; previously, Department of Periodontics and Oral Medicine, School of Dentistry, University of Michigan, Ann Arbor, MI

$\uparrow$ Department of Periodontics and Oral Medicine, School of Dentistry, University of Michigan.

$\ddagger$ Department of Biologic Materials and Sciences, School of Dentistry, University of Michigan.
}

1 epairing mucogingival defects that maintain esthetic and functional tissue is a challenge. Gingival recession and inadequate attached gingiva have been considered precipitating factors for root sensitivity, root caries, increased gingival inflammation, and impaired esthetics. Gingival recession is also one of the more common concerns for the patient and dentist because of root sensitivity and unappealing esthetics. It was reported that 58\% of the American population $>30$ years of age has one or more sites with gingival recession $>1 \mathrm{~mm} .^{1,2}$

Numerous surgical procedures have been developed and used clinically to treat gingival recession. These include the laterally positioned flap, double papilla flap, coronally advanced flap (CAF), free gingival grafts, subepithelial connective tissue grafts (SCTGs), guided tissue regeneration, acellular dermal matrix allografts, and a combination of the above. ${ }^{3-10}$ Among these procedures, the SCTG has been regarded as the most reliable and predictable procedure in achieving root coverage (RC) while maintaining the most esthetic outcome. 11

doi: 10.1902/jop.2009.080673 
Two versions of the SCTG procedure adopted by most clinicians were described by Langer and Langer ${ }^{7}$ and Bouchard et al. ${ }^{12}$ Langer and Langer ${ }^{7}$ originally described the technique with a parallel incision on the palate to harvest the ideal graft thickness (average of $1.5 \mathrm{~mm}$ ), which includes leaving a strip of palatal keratinized epithelium. This was to aid suturing and to provide more rapid epithelialization. The epithelium on the graft was believed to help smooth the transition of the grafted tissue to the existing epithelium and to provide a better tissue color match. The second technique removes all of the epithelium so the graft can be stabilized better and completely covered by coronally positioning the flap to provide a smoother, more esthetic gingival contour. ${ }^{12,13}$

Several modifications have been developed in managing the connective tissue (CT) graft and the recipient site flap. ${ }^{14-16}$ Nelson ${ }^{16}$ proposed using a fullthickness flap with two vertical releasing incisions to coronally advance the flap and cover the graft. Raetzke ${ }^{14}$ demonstrated an "envelope" technique with no releasing incisions to secure the donor CT into an envelope created around the denuded root surface of a single gingival recession defect. In addition, Zabalegui et al. ${ }^{15}$ proposed a "tunnel" technique. This is based on sharp dissection to construct a tunnel under the gingival tissue by means of a sulcular incision that extends below the mucogingival line without reflecting the gingival papillae.

Numerous studies ${ }^{11,17-19}$ have been performed to compare the outcome of different surgical techniques. da Silva et al. ${ }^{19}$ suggested that if the treatment goal is aimed at increasing gingival dimensions (e.g., keratinized tissue width and gingival/mucosal thickness), the CAF + SCTG is preferred for a better long-term outcome. Although studies 12,14,15,17-19 confirmed that the SCTG is a predictable procedure, limited evidence is available as to whether the epithelial collar on an SCTG provides better clinical outcomes compared to SCTG without the epithelium. Hence, the goal of this study was to compare specific clinical outcomes (e.g., percentage of RC, keratinized gingiva [KG] gain, and gingival thickness gain) after an SCTG with or without an epithelial collar was covered with a coronally advanced envelope flap.

\section{MATERIALS AND METHODS}

Twenty subjects diagnosed with one or more Miller ${ }^{20}$ Class I or II gingival recessions $\geq 2 \mathrm{~mm}$ on anterior teeth and premolars were recruited from the patient pool at the University of Michigan School of Dentistry. A power analysis determined that 20 sites would be required for $>80 \%$ chance to detect a 1 -mm difference in the amount of RC between two procedures.

The subjects were recruited based on the following inclusion criteria: a healthy adult aged 18 years or older, Miller ${ }^{20}$ Class I or II gingival recession $\geq 2 \mathrm{~mm}$ on mandibular or maxillary anterior teeth or premolars, no missing adjacent or opposing teeth, good oral hygiene, and no endodontic-related lesions. Exclusion criteria were long-term ( $>2$ weeks) use of antibiotics in the past 3 months; tooth mobility; patients taking steroids or any medications known to cause gingival enlargement; pregnancy or attempting to get pregnant; unstable systemic conditions, such as uncontrolled diabetes, that were not suitable for the surgery; and smoking.

A written consent was obtained from all patients, and they were screened by the primary researcher (HB) according to the inclusion/exclusion criteria. The patients were randomly assigned to receive an SCTG with a retained epithelial cuff + CAF (SCTGE) or an SCTG without an epithelial cuff + CAF (SCTGN). Subject randomization was performed by drawing a card from a bag at the time of each surgical appointment.

The study was approved by the Institutional Review Board (IRB) at the University of Michigan and was conducted from September 2006 to June 2008.

\section{Clinical Parameters}

Clinical parameters evaluated for the study included recession depth (RD), recession width (RW), width of the keratinized gingiva (KW), probing depth (PD), clinical attachment level (CAL), gingival index (GI), ${ }^{21}$ and plaque index (PI). ${ }^{22}$ The measurements were performed at baseline (SCTG surgery) and at 3 and 6 months postoperatively by a masked calibrated examiner with a University of North Carolina probe, to the nearest $0.5 \mathrm{~mm}$, using a prefabricated acrylic resin stent with markings (Fig. 1). RD was measured at the mid-buccal point of the tooth by subtracting the distance between the stent and the cemento-enamel junction (CEJ) from the distance between the stent and the most coronal point of the free gingiva; RW was measured $1 \mathrm{~mm}$ apical to the CEJ. KW was measured on the mid-buccal point from the free gingival margin to the mucogingival junction (MGJ). PD was measured axially from the free gingival margin to the most apical part of the sulcus at the mesial, mid-buccal, and distal aspects. Along with the clinical measurements, thickness of the recipient gingival tissue (GT) was measured at baseline $3 \mathrm{~mm}$ apical to the free gingival margin (at the mid-buccal aspect) by penetrating a \#15 endodontic file with a rubber stop into the tissue.

The wound healing index $(\mathrm{WHI})^{23}$ was evaluated using the following criteria: score $1=$ uneventful healing with no gingival edema, erythema, suppuration, patient discomfort, or flap dehiscence; score 2 = uneventful healing with slight gingival edema, erythema, patient discomfort, or flap dehiscence but no suppuration; and score 3 = poor wound healing with 


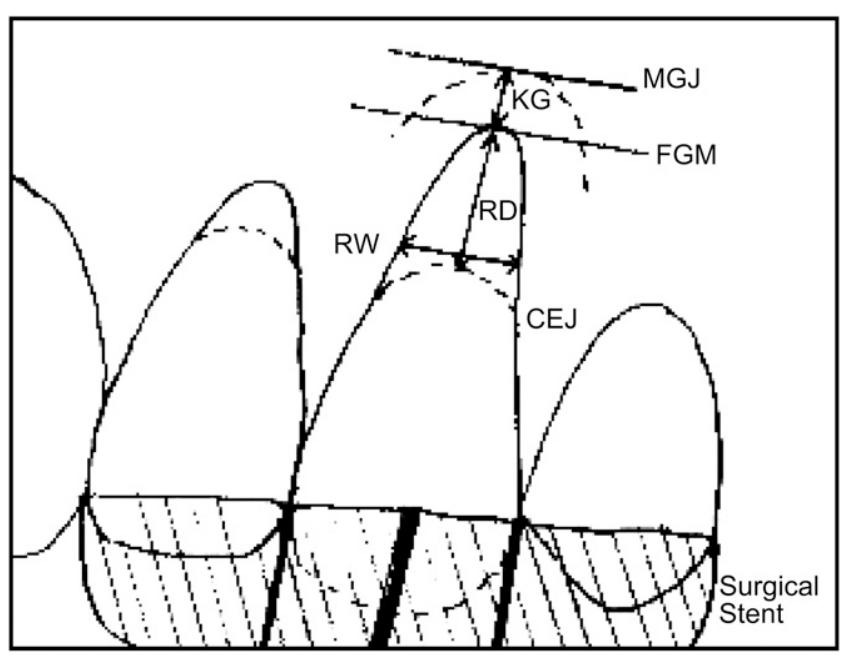

Figure I.

References for the clinical measurements. FGM = free gingival margin.

significant gingival edema, erythema, patient discomfort, flap dehiscence, or any suppuration. ${ }^{23} \mathrm{Fi}$ nally, the percentage of RC was calculated as ([RD presurgical - RD post-surgical]/RD presurgical) $\times 100$ at each observation period.

\section{Surgical Procedures (Figs. 2 and 3)}

All surgical procedures were performed by one investigator $(\mathrm{HB})$ under local anesthesia with $2 \%$ lidocaine. The recipient site was prepared by a sulcular incision and full-thickness flap to the MGJ, with partial-thickness dissection beyond the MGJ. The distance between the tip of the papillae and the incision line on the papillae was $1 \mathrm{~mm}$ apical to the depth of recession. An envelope flap was made, and the exposed root surface, including the CEJ, was thoroughly root planed and recontoured using hand and rotary instruments.

At the palatal donor site, a horizontal incision was made with a \#15 blade $\sim 3 \mathrm{~mm}$ apical to the free gingival margin. For the SCTGN, a second incision was made with a \#15 blade, undermining and splitting the palatal flap. Vertical incisions were placed anteriorly and posteriorly beneath the palatal flap, and another horizontal incision was made apically on the CT to sever the graft tissue. A periosteal elevator was used to separate the graft periosteum from the bone. The SCTGE followed the same procedure as the SCTGN, except that the second horizontal incision was made $2 \mathrm{~mm}$ apical to the initial incision line to include a 2-mm epithelial collar on the graft.

The CT graft was trimmed and placed into the envelope-type recipient flap and immobilized against the tooth using a sling suture with 5-0 chromic gut. The flap was coronally advanced with minimal tension, $1 \mathrm{~mm}$ over the CEJ. When the graft contained the epithelial cuff, it was left exposed above the flap margin. Then, the flap was well stabilized with a sling suture placed at each flap papilla.

Postoperative instructions were provided to each patient verbally and in written form. To minimize potential infection, amoxicillin (500 mg, three times a day) was prescribed for 7 days; azithromycin (500 mg, every day) was prescribed for 3 days if the patient was allergic to penicillin. The patients were instructed to rinse carefully with warm salt water three times a day for the first 2 days after treatment, followed by $0.12 \%$ chlorhexidine rinse (twice a day) to control plaque for 2 weeks. Sutures were removed 10 to 14 days postoperatively. The patients were observed again at 1,3, and 6 months after the surgery. Oral hygiene instruction and professional cleaning were provided at each follow-up visit.

\section{Statistical Analysis}

The data are presented as mean \pm SD for each variable. The summary statistics were generated for each group at baseline and at 3 and 6 months. Statistical analysis was performed using a statistical package. $\S$ An independent-samples $t$ test was performed to compare the clinical parameters between the two groups at 3 and 6 months, whereas a pairedsamples $t$ test was carried out to compare treatment outcomes within the groups at each follow-up point. The demographics were also compared between the two groups at baseline to ensure that they were comparable with regard to age and gender. The significance level for rejection of the null hypothesis was set at $\alpha=0.05$.

\section{RESULTS}

Among the 20 subjects, there were eight males and 12 females, aged 20 to 60 years, with a mean age of 42.6 years (Table 1). The SCTGE group consisted of five maxillary premolars, four maxillary canines, and one mandibular premolar, whereas the SCTGN group consisted of two maxillary canines, one maxillary premolar, and seven mandibular premolars.

\section{Comparison of Clinical Parameters Between the Groups}

The baseline clinical parameters were not statistically significantly different between the two groups $(P>0.05$; Table 2$)$. The mean RD was $2.45 \pm 0.50$ $\mathrm{mm}$ and $2.53 \pm 0.63 \mathrm{~mm}$ for SCTGE and SCTGN groups, respectively. The mean KW at baseline was $2.00 \pm 0.88 \mathrm{~mm}$ for the SCTGE group and $1.35 \pm$ $0.75 \mathrm{~mm}$ for the SCTGN group.

The mean RC for the SCTGE group was $95.50 \% \pm$ $9.56 \%$ and $97.50 \% \pm 7.90 \%$ at 3 and 6 months,

$\S$ SPSS statistical package version 16.0, SPSS for Windows, SPSS, Chicago, IL. 

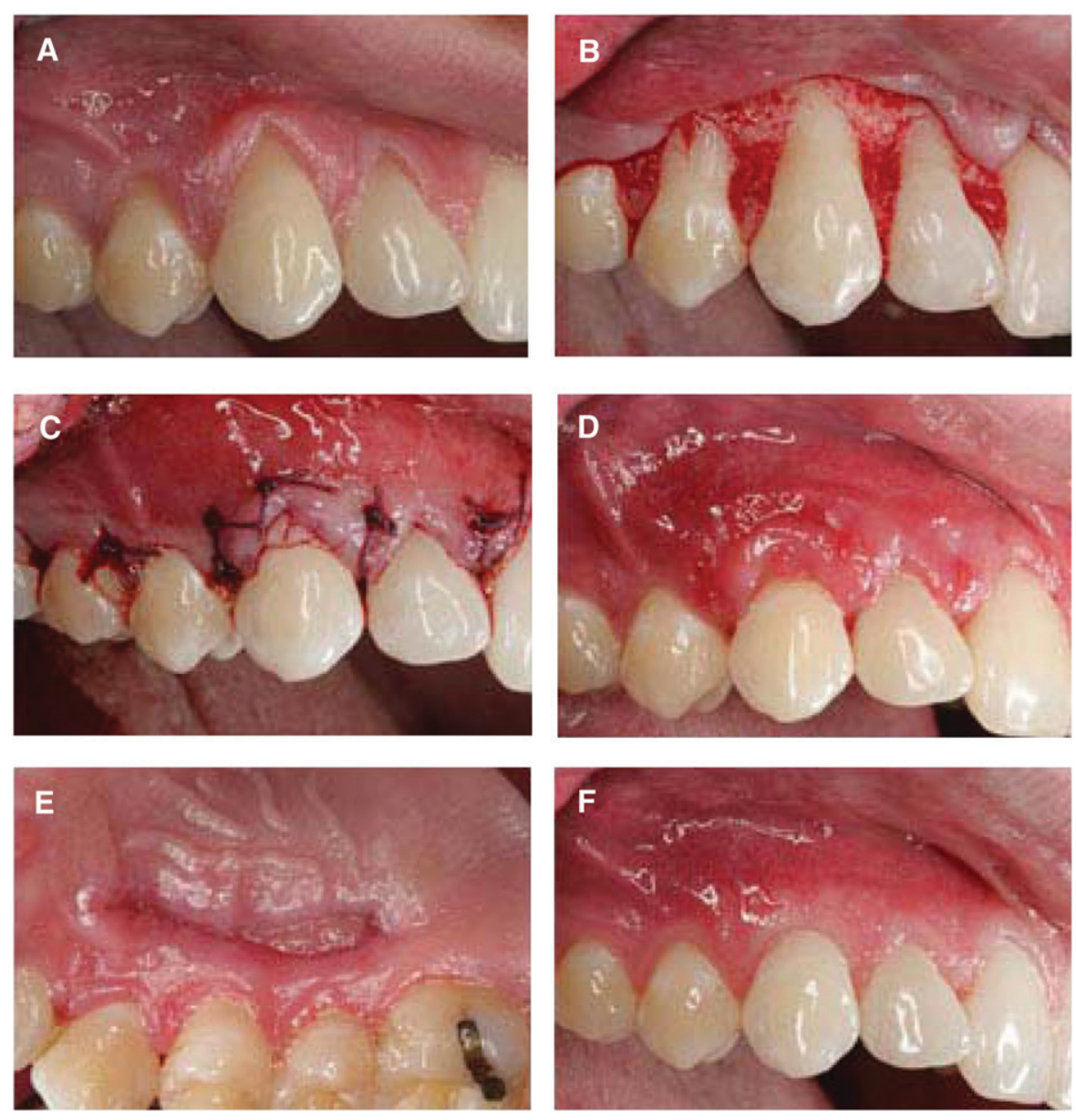

Figure 2.

Surgical procedures and results in the SCGTE group. A) Baseline recession defect. B) Incision and flap reflection. C) Sutured graft and flap. D) 2-week postoperative follow-up of recipient site.

E) 2-week postoperative follow-up of donor site. F) 6-month follow-up.

respectively, whereas for the SCTGN group it was $87.40 \% \pm 17.46 \%$ and $89.10 \% \pm 25.93 \%$. No statistically significant difference between the groups was noted at either time period ( $P>0.05$; Table 3$)$. At 3 months, KW for the SCTGE group measured $4.10 \pm$ $1.10 \mathrm{~mm}$, whereas for the SCTGN group it measured $2.75 \pm 0.68 \mathrm{~mm}$. Mean RW was $0 \mathrm{~mm}$ and $1.20 \pm 1.60$ $\mathrm{mm}$ for SCTGE and SCTGN groups, respectively. KW and RW were statistically significantly different between the two groups, indicating that the SCTGE group gained significantly more keratinized tissue and had less RW $(P<0.05$; Table 3$)$. However, significant differences were not seen at 6 months. Eight of 10 subjects in the SCTGE group and six of 10 subjects in the SCTGN group achieved complete RC at 3 months, whereas nine of 10 and seven of 10 subjects in SCTGE and SCTGN groups, respectively, showed complete RC at 6 months. Overall, 16 of 20 subjects had $100 \% \mathrm{RC}$ at 6 months.

The RD at 3 months was $-0.20 \pm 0.72 \mathrm{~mm}$ for the SCTGE group and $0.25 \pm 0.59 \mathrm{~mm}$ for the SCTGN group, whereas at 6 months it was $-0.35 \pm 0.85 \mathrm{~mm}$ and $0.10 \pm$ $0.84 \mathrm{~mm}$ for SCTGE and SCTGN groups, respectively. GT was $2.25 \pm 0.63 \mathrm{~mm}$ and $2.10 \pm 0.66$ $\mathrm{mm}$ for the SCTGE group at 3 and 6 months, respectively, and $1.75 \pm 0.59 \mathrm{~mm}$ and $1.65 \pm 0.53$ $\mathrm{mm}$ in the SCTGN group. There were no significant differences in RD, GT, CAL, PD, GT, PI, GI, or WHI between the groups at 3 or 6 months $(P>0.05)$. Both groups had $\sim 0.15 \mathrm{~mm}$ creeping attachment gain from 3 to 6 months.

\section{Changes in Clinical Parameters Within the Groups}

The mean increase in KW from baseline to 3 and 6 months was $2.10 \pm 1.10 \mathrm{~mm}$ and $1.40 \pm 0.70$ $\mathrm{mm}$, respectively, for the SCTGE group and $1.85 \pm 1.72 \mathrm{~mm}$ and $1.40 \pm 0.74 \mathrm{~mm}$ for the SCTGN group. The mean reduction in RD from baseline was $2.65 \pm 0.75$ $\mathrm{mm}$ and $2.80 \pm 1.01 \mathrm{~mm}$ for the SCTGE group at 3 and 6 months, respectively, whereas it was $2.20 \pm 0.42 \mathrm{~mm}$ and $2.35 \pm 0.82$ $\mathrm{mm}$ in the SCTGN group. Changes in KW and RD were statistically significantly different compared to baseline $(P<0.001$; Tables 2 and 3). GT, CAL, and RW also exhibited statistically significant differences at 3 and 6 months compared to baseline in both groups $(P<0.001$; Tables 2 and 3). However, PD, PI, and GI showed no significant differences at 3 and 6 months compared to baseline in either group ( $P>0.05$; Tables 2 and 3 ).

\section{Recipient Site Gingival Flap Thickness and $R C$ Outcomes}

With regard to GT, mean RD changes from baseline to 3 months were $2.50 \pm 0.00 \mathrm{~mm}$ for subjects with 0.5 $\mathrm{mm} \mathrm{GT}, 2.54 \pm 0.69 \mathrm{~mm}$ for $1.0-\mathrm{mm} \mathrm{GT}$, and $1.83 \pm$ $0.29 \mathrm{~mm}$ for $1.5-\mathrm{mm}$ GT. At 6 months, the corresponding changes in RD were $2.33 \pm 0.29 \mathrm{~mm}$, $2.78 \pm 1.01 \mathrm{~mm}$, and $1.83 \pm 0.29 \mathrm{~mm}$. The results showed no statistically significant relationship between RC outcomes and gingival thickness.

\section{DISCUSSION}

SCTG procedures are considered one of the most predictable methods for RC as well as for increasing KG width and tissue thickness. The purpose of this study 

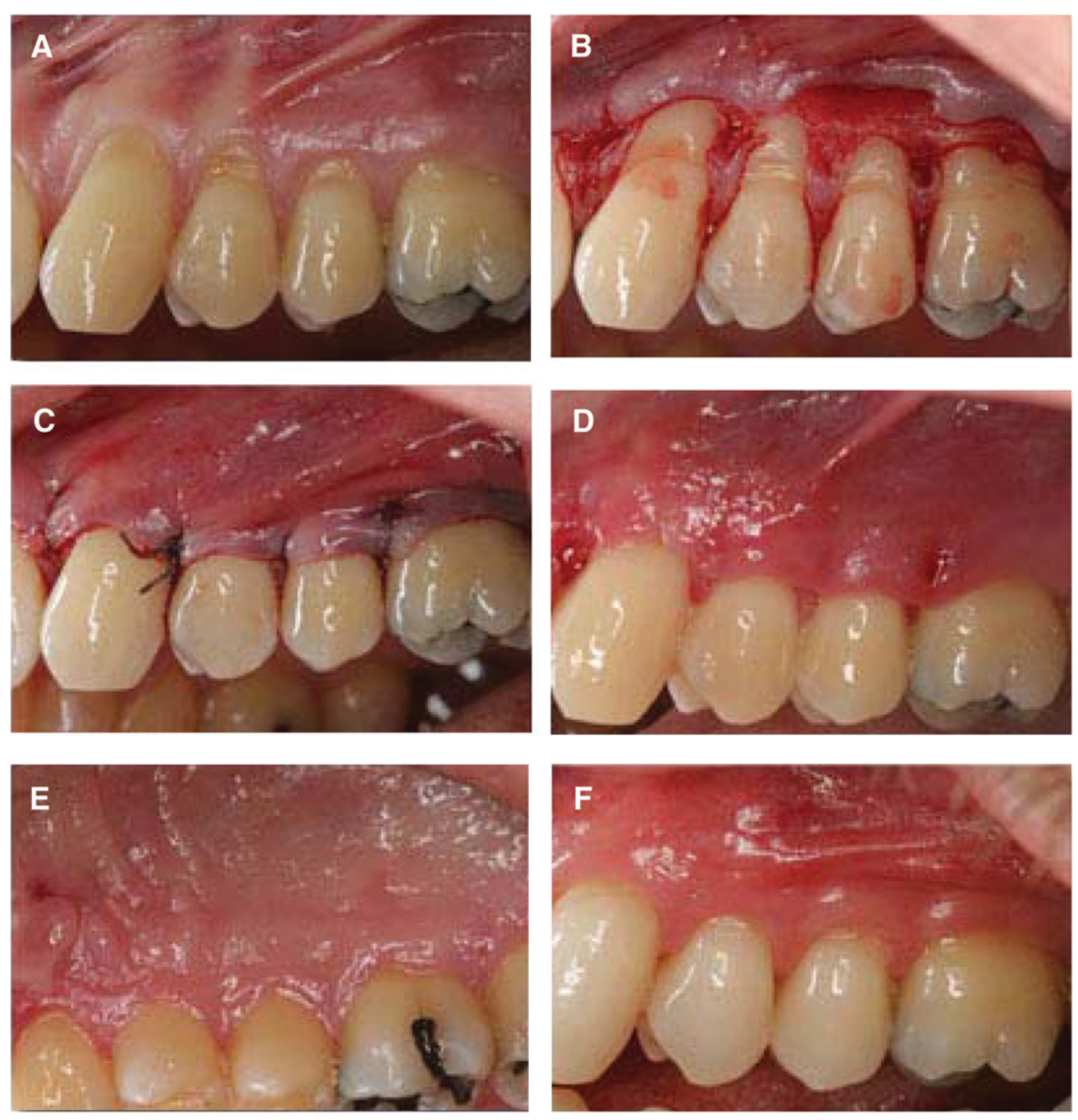

Figure 3.

Surgical procedures and results in the SCGTN group. A) Baseline recession defect. B) Incision and flap reflection. C) Sutured graft and flap. D) 2-week postoperative follow-up of recipient site.

E) 2-week postoperative follow-up of donor site. F) 6-month follow-up.

In this study, the SCTGE group showed a mean RC of $98 \%$ at 6 months compared to $89 \%$ in the SCTGN group, with no significant difference between the groups. The results of this study are in the range of other reported studies $^{12,19,24-28}$ using an SCTG. These studies reported a mean $\mathrm{RC}$ ranging from $65.5 \%$ to $99 \%$. In a study ${ }^{25}$ using a similar method to our study, the group with the envelope flap + connective tissue graft (CTG) + epithelial collar had a mean RC of $89.6 \%$ compared to $94.7 \%$ in the CAF + CTG group. The difference between their CAF + CTG group (94.7\%) and the SCTGN group in our study (89.1\%) may be attributed to the use of vertical releasing incisions in their study. It can be speculated that vertical releasing incisions facilitate more coronal overcorrection and less tension of the overlying flap, possibly leading to better RC. This is supported by the study of Pini Prato et al., ${ }^{29}$ who indicated that the more coronal the level of the gingival margin after suturing, the greater the probability of RC. The anatomic location of the selected teeth is another factor that might have influenced the different outcomes

Table I.

\section{Baseline Demographics}

\begin{tabular}{lccr}
\hline Demographic & $\begin{array}{c}\text { SCTGE } \\
(n=10)\end{array}$ & $\begin{array}{c}\text { SCTGN } \\
(n=10)\end{array}$ & $P$ Value \\
\hline Age (years; mean \pm SD) & $40.8 \pm 11.3$ & $44.3 \pm 11.7$ & 0.290 \\
Gender $(n)$ & & & \\
$\quad$ Male & 3 & 5 & 0.679 \\
$\quad$ Female & 7 & 5 & \\
Arch $(n)$ & & & \\
$\quad$ Maxilla & 9 & 3 & $<0.05$ \\
Mandible & 1 & 7 & \\
\hline
\end{tabular}

was to compare the clinical outcomes (e.g., percentage of RC, KG gain, and gingival thickness gain) after the CT graft with or without a collar of epithelium. All treatments were performed in conjunction with a CAF using an envelope flap. between the two groups in our study or with other studies. Our SCTGE group had only one mandibular tooth compared to seven mandibular teeth in the SCTGN group. Differences in the muscle pull or movement during function of the mandibular teeth are believed to result in less graft stabilization and less favorable clinical outcomes. This belief corresponds with other studies ${ }^{30-32}$ showing that maxillary teeth have more predictable RC than mandibular teeth.

Complete RC was seen in nine of 10 and seven of 10 subjects from SCTGE and SCTGN groups, respectively. Although statistically non-significant, the SCTGE group showed better RC at 6 months posttreatment. The keratinized epithelium may have provided better initial graft tissue fluid seal during the healing process. The complete RC directly influenced the outcome of RD and RW in our study, especially RW. Having three subjects without complete RC in the SCTGN group, compared to only one subject in the SCTGE group, may explain why there was a significant difference in RW at 3 months. However, this 
Table 2.

\section{Baseline Clinical Parameters (mean \pm SD)}

\begin{tabular}{lccc}
\hline Parameter & SCTGE $(n=10)$ & SCTGN $(n=10)$ & $P$ Value \\
\hline RD $(\mathrm{mm})$ & $2.45 \pm 0.50$ & $2.53 \pm 0.63$ & 0.719 \\
KW $(\mathrm{mm})$ & $2.00 \pm 0.88$ & $1.35 \pm 0.75$ & 0.092 \\
CAL $(\mathrm{mm})$ & $3.85 \pm 0.85$ & $3.65 \pm 0.67$ & 0.566 \\
PD $(\mathrm{mm})$ & $1.40 \pm 0.46$ & $1.20 \pm 0.35$ & 0.288 \\
RW $(\mathrm{mm})$ & $3.55 \pm 0.37$ & $2.95 \pm 1.28$ & 0.171 \\
GT $(\mathrm{mm})$ & $1.10 \pm 0.21$ & $0.90 \pm 0.32$ & 0.113 \\
PI & $0.30 \pm 0.48$ & $0.70 \pm 0.48$ & 0.081 \\
Gl & $0.70 \pm 0.68$ & $1.10 \pm 0.32$ & 0.107 \\
\hline
\end{tabular}

difference was significantly reduced at 6 months. Future studies with a larger sample size are needed to validate this finding.

The two most commonly used surgical techniques for SCTG are described by Langer and Langer, ${ }^{7}$ leaving a collar of epithelium attached; and Bouchard et al., ${ }^{12}$ removing the epithelial collar. It can be speculated that the collar of epithelium aids suturing and provides a smoother junctional color and contour and more rapid healing to the existing epithelium. However, in a study ${ }^{12}$ comparing SCTGN and SCTGE, the esthetic assessment by independent examiners favored SCTGN. In our study, several technical concerns were raised when the collar of epithelium was left on the graft. During suturing of the envelope flap, it was almost impossible to prevent the flap from lying on top of the graft epithelium, especially in the papillary area. This created a concern about possible cyst formation. Although no complication was noted in our study, this issue needs to be addressed carefully. Second, unlike the proposal of a smooth junction with the existing epithelium, several subjects exhibited a demarcation line between the existing flap and the graft during early healing. This may require a second procedure (gingivoplasty), especially in the esthetic zone. The third limitation is that the donor site in the SCTGE group healed more slowly than the SCTGN group. In general, a 2-mm clot-filled depression was found in the palatal epithelium at 2 weeks post-surgery, possibly leading to patient discomfort in the early stage of healing. However, no difference in the clinical healing between the two groups was found at 1 month.

The SCTG procedures increased the mean KG width for both groups at 3 and 6 months. A significantly wider amount of KG was noted in the SCTGE
Table 3.

Comparison of Clinical Parameters at 3 and 6 Months (mean \pm SD)

\begin{tabular}{|c|c|c|c|}
\hline Parameter & SCTGE $(n=10)$ & SCTGN $(n=10)$ & $P$ Value \\
\hline \multicolumn{4}{|l|}{$\mathrm{RD}(\mathrm{mm})$} \\
\hline 3 months & $-0.20 \pm 0.72$ & $0.25 \pm 0.59$ & 0.142 \\
\hline 6 months & $-0.35 \pm 0.85$ & $0.10 \pm 0.84$ & 0.250 \\
\hline \multicolumn{4}{|l|}{$\mathrm{KW}(\mathrm{mm})$} \\
\hline 3 months & $4.10 \pm 1.10$ & $2.75 \pm 0.68$ & $0.004 *$ \\
\hline 6 months & $3.85 \pm 1.80$ & $2.75 \pm 0.76$ & 0.091 \\
\hline \multicolumn{4}{|l|}{$\mathrm{RC}(\%)$} \\
\hline 3 months & $95.50 \pm 9.56$ & $87.40 \pm 17.46$ & 0.219 \\
\hline 6 months & $97.50 \pm 7.90$ & $89.10 \pm 25.93$ & 0.340 \\
\hline \multicolumn{4}{|l|}{ CAL (mm) } \\
\hline 3 months & $1.30 \pm 0.82$ & $|.50 \pm 0.7|$ & 0.567 \\
\hline 6 months & $1.25 \pm 0.75$ & $1.40 \pm 10.5$ & 0.718 \\
\hline \multicolumn{4}{|l|}{ PD (mm) } \\
\hline 3 months & $1.50 \pm 0.47$ & $1.25 \pm 0.35$ & 0.196 \\
\hline 6 months & $1.60 \pm 0.62$ & $1.30 \pm 0.54$ & 0.260 \\
\hline \multicolumn{4}{|l|}{$\mathrm{RW}(\mathrm{mm})$} \\
\hline 3 months & 0 & $1.20 \pm 1.60$ & $0.029 *$ \\
\hline 6 months & 0 & $0.60 \pm 1.29$ & 0.174 \\
\hline \multicolumn{4}{|l|}{ GT (mm) } \\
\hline 3 months & $2.25 \pm 0.63$ & $1.75 \pm 0.59$ & 0.085 \\
\hline 6 months & $2.10 \pm 0.66$ & $1.65 \pm 0.53$ & 0.109 \\
\hline \multicolumn{4}{|l|}{$\mathrm{Pl}$} \\
\hline 3 months & $0.40 \pm 0.52$ & $0.60 \pm 0.52$ & 0.398 \\
\hline 6 months & $0.40 \pm 0.52$ & $0.70 \pm 0.48$ & 0.196 \\
\hline \multicolumn{4}{|l|}{ Gl } \\
\hline 3 months & $0.70 \pm 0.48$ & $1.00 \pm 0.47$ & 0.177 \\
\hline 6 months & $0.70 \pm 0.48$ & $1.00 \pm 0.47$ & 0.177 \\
\hline
\end{tabular}

* Statistically significant $(P<0.05)$.

group at 3 months, which implies that the epithelial collar might have contributed to KW gain during the initial stage of healing. An increase in KW after an SCTG procedure is controversial. Studies $^{25,26,28,33-35}$ showed a wide range of increase in KW postoperatively from 0.7 to $4.0 \mathrm{~mm}$. Our results for KW gain in the SCTGN group were larger than the results of Cordioli et al., ${ }^{25}$ who found a $0.7-\mathrm{mm}$ increase in KW. A possible explanation for the difference is that in their study, the CAF + SCTG group without the epithelium had the most coronal portion of the CT graft exposed above the flap, resulting in less KG, possibly from necrosis. Conversely, our SCTGE group showed similar results to the study of Cordioli et al. ${ }^{25}$ They reported that the KW post-surgically was mathematically correlated with baseline KW. This loosely correlates with our baseline measurements. 
Regarding the longevity of KW, a study ${ }^{34}$ observed that an initial KW gain of $1.95 \mathrm{~mm}$ remained stable for up to 3 years. Further investigations with a bigger sample size and a longer observation period are needed to confirm the results.

There is no doubt that placing quality SCTG underneath the donor site flap would result in a thicker gingival tissue. However, the stability of the augmented tissue thickness remains a question. Our data showed a mean GT gain of $1.0 \mathrm{~mm}$ for the SCTGE group and $0.75 \mathrm{~mm}$ for the SCTGN group at 6 months. There was no statistically significant difference between the two groups. The increased GT in the current study is approximately twice that reported by da Silva et al. ${ }^{19}$ ( $0.44 \mathrm{~mm}$ at 6 months) and similar to the result of Müller et al. ${ }^{36}(0.7 \mathrm{~mm}$ mean gain). The difference between our data and those of da Silva et al. ${ }^{19}$ may be due to differences in the measurement technique and scale. Our study measured to the nearest $0.5 \mathrm{~mm}$, whereas their study measured the thickness to the nearest $0.1 \mathrm{~mm}$. da Silva et al. ${ }^{19}$ also addressed the tissue contraction of the thickness during healing. Shrinkage of GT during healing of the free CTG was also reported in the literature. ${ }^{37,38} \mathrm{Edel}^{38}$ reported graft shrinkage of $28 \%$, and Orsini et al. ${ }^{37}$ demonstrated shrinkage of $28.4 \%$ at 1 month, $37.2 \%$ at 26 weeks, and $43.25 \%$ at 52 weeks. Although these measurements were performed in two dimensions on the free gingival graft, we might be able to apply this term to connective tissue grafts. The graft contracts volumetrically (length, width, and thickness) as a result of primary and secondary contraction, as well as necrosis and soft tissue remodeling. It would be clinically helpful to understand the factors involved in the graft contraction and the timing of graft stabilization. Future research in this area is encouraged.

The importance of GT (biotype) on RC has been discussed in many studies. ${ }^{39-41}$ Baldi et al. ${ }^{40}$ reported that flap thickness $\geq 0.8 \mathrm{~mm}$ was required to predictably gain complete RC. Huang et al. ${ }^{39}$ suggested that initial GT $>1.2 \mathrm{~mm}$ was more favorable for complete RC than a far more delicate, thinner GT flap. A systematic review ${ }^{41}$ concluded that a positive association exists between GT and RC; a critical threshold thickness of $>1.1 \mathrm{~mm}$ was suggested from the analysis. However, our data were not in agreement with those observations. To the contrary, subjects who had thicker GT ( $\geq 1.5 \mathrm{~mm}$ flap thickness) had the least amount of RD reduction at 6 months, although the mean RC was similar. No significant differences with regard to the location of the tooth in the arch, baseline $\mathrm{RD}$, and baseline $\mathrm{KW}$ were noted between the thicker and thinner tissue $(0.5 \mathrm{~mm})$. It is suggested that factors such as the recipient site flap and graft tissue stability during initial wound healing, the post-suturing coronal position (i.e., beyond the CEJ) of the recipient flap margin, and flap tension after suturing outweigh the effect of flap thickness on RC. Moreover, postoperative patient compliance can be a critical, unmeasured factor influencing clinical outcomes. We had a minimal number of subjects in our study with 0.5 or $1.5-\mathrm{mm}$ flap thickness; therefore, it is difficult to draw any definitive conclusion from the study results.

Several limitations existed in our study. First, the small subject number and short observation period limit generalizing the study results; in particular, the stability of the KW or GT warrants a longer observation. Second, although the subjects were randomly assigned to each group, the SCTGE group had only one mandibular tooth, which may not have eliminated the influence of muscle pull on the flap or the stability of the graft. Third, the recession defects included in the study were relatively small, which made the detection of outcome differences between the two groups challenging. Another limitation is that the graft thickness/size, tension on the flap, coronal position of the recipient site gingival flap, and postoperative maintenance by the patients could not be standardized for accurate comparison between the groups.

\section{CONCLUSIONS}

Both SCTG techniques (with and without the epithelial collar) provided predictable and successful RC $(\geq 89 \%)$. The retained epithelial collar on the SCTG did not provide a significant benefit with regard to the clinical parameters, other than the short-term increase in KW. Therefore, it is suggested that the retained epithelial collar on an SCTG may not result in a better clinical outcome compared to one without an epithelial collar.

\section{ACKNOWLEDGMENTS}

This study was supported by the Periodontal Graduate Student Research Fund, University of Michigan. The authors thank Mary Layher, research associate, Graduate Periodontics, University of Michigan, for her assistance with monitoring the project and coordinating IRB-related issues. The authors report no conflicts of interest related to this article.

\section{REFERENCES}

1. Kassab MM, Cohen RE. The etiology and prevalence of gingival recession. J Am Dent Assoc 2003;134:220225.

2. Albandar JM, Kingman A. Gingival recession, gingival bleeding, and dental calculus in adults 30 years of age and older in the United States, 1988-1994. J Periodontol 1999;70:30-43.

3. Caffesse RG, Alspach SR, Morrison EC, Burgett FG. Lateral sliding flaps with and without citric acid. Int $J$ Periodontics Restorative Dent 1987;7:42-57. 
4. Grupe HE. Modified technique for the sliding flap operation. J Periodontol 1966;37:491-495.

5. Pini-Prato G, Baldi C, Pagliaro U, et al. Coronally advanced flap procedure for root coverage. Treatment of root surface: Root planing versus polishing. J Periodontol 1999;70:1064-1076.

6. Sullivan HC, Atkins JH. Free autogenous gingival grafts. 1. Principles of successful grafting. Periodontics 1968;6:5-13.

7. Langer B, Langer L. Subepithelial connective tissue graft technique for root coverage. J Periodontol 1985; 56:715-720.

8. Cortellini P, Clauser C, Prato GP. Histologic assessment of new attachment following the treatment of a human buccal recession by means of a guided tissue regeneration procedure. J Periodontol 1993; 64:387-391.

9. Harris RJ. GTR for root coverage: A long-term followup. Int J Periodontics Restorative Dent 2002;22:55-61.

10. Tal H. Subgingival acellular dermal matrix allograft for the treatment of gingival recession: A case report. $J$ Periodontol 1999;70:1118-1124.

11. Wennström JL, Zucchelli G. Increased gingival dimensions. A significant factor for successful outcome of root coverage procedures? A 2-year prospective clinical study. J Clin Periodontol 1996;23:770-777.

12. Bouchard P, Etienne D, Ouhayoun JP, Nilvéus R. Subepithelial connective tissue grafts in the treatment of gingival recessions. A comparative study of 2 procedures. J Periodontol 1994;65:929-936.

13. Bouchard P, Nilvéus R, Etienne D. Clinical evaluation of tetracycline $\mathrm{HCl}$ conditioning in the treatment of gingival recessions. A comparative study. J Periodontol 1997;68:262-269.

14. Raetzke PB. Covering localized areas of root exposure employing the "envelope" technique. J Periodontol 1985;56:397-402.

15. Zabalegui I, Sicilia A, Cambra J, Gil J, Sanz M. Treatment of multiple adjacent gingival recessions with the tunnel subepithelial connective tissue graft: A clinical report. Int J Periodontics Restorative Dent 1999;19:199-206.

16. Nelson SW. The subpedicle connective tissue graft. A bilaminar reconstructive procedure for the coverage of denuded root surfaces. J Periodontol 1987;58:95-102.

17. Tözüm TF, Keçeli HG, Güncü GN, Hatipoğlu H, Sengün D. Treatment of gingival recession: Comparison of two techniques of subepithelial connective tissue graft. J Periodontol 2005;76:1842-1848.

18. Harris RJ, Miller LH, Harris CR, Miller RJ. A comparison of three techniques to obtain root coverage on mandibular incisors. J Periodontol 2005;76:1758-1767.

19. da Silva RC, Joly JC, de Lima AF, Tatakis DN. Root coverage using the coronally positioned flap with or without a subepithelial connective tissue graft. J Periodontol 2004;75:413-419.

20. Miller PD Jr. A classification of marginal tissue recession. Int J Periodontics Restorative Dent 1985;5:8-13.

21. Löe $H$. The gingival index, the plaque index and the retention index systems. J Periodontol 1967;38 (Suppl.):610-616.

22. Silness J, Löe H. Periodontal disease in pregnancy. II. Correlation between oral hygiene and periodontal condition. Acta Odontol Scand 1964;22:121-135.

23. Huang LH, Neiva RE, Soehren SE, Giannobile WV, Wang HL. The effect of platelet-rich plasma on the coronally advanced flap root coverage procedure: A pilot human trial. J Periodontol 2005;76:1768-1777.
24. Harris RJ, Harris LE, Harris CR, Harris AJ. Evaluation of root coverage with two connective tissue grafts obtained from the same location. Int $J$ Periodontics Restorative Dent 2007;27:333-339.

25. Cordioli G, Mortarino C, Chierico A, Grusovin MG, Majzoub Z. Comparison of 2 techniques of subepithelial connective tissue graft in the treatment of gingival recessions. J Periodontol 2001;72:1470-1476.

26. Dembowska E, Drozdzik A. Subepithelial connective tissue graft in the treatment of multiple gingival recession. Oral Surg Oral Med Oral Pathol Oral Radiol Endod 2007;104:e1-e7.

27. Vergara JA, Caffesse RG. Localized gingival recessions treated with the original envelope technique: A report of 50 consecutive patients. J Periodontol 2004; 75:1397-1403.

28. Carvalho PF, da Silva RC, Cury PR, Joly JC. Modified coronally advanced flap associated with a subepithelial connective tissue graft for the treatment of adjacent multiple gingival recessions. J Periodontol 2006; 77:1901-1906.

29. Pini Prato GP, Baldi C, Nieri M, et al. Coronally advanced flap: The post-surgical position of the gingival margin is an important factor for achieving complete root coverage. J Periodontol 2005;76:713-722.

30. Harris RJ. A comparison of 2 root coverage techniques: Guided tissue regeneration with a bioabsorbable matrix style membrane versus a connective tissue graft combined with a coronally positioned pedicle graft without vertical incisions. Results of a series of consecutive cases. J Periodontol 1998;69:14261434.

31. Rosetti EP, Marcantonio RA, Rossa C Jr., Chaves ES, Goissis G, Marcantonio E Jr. Treatment of gingival recession: Comparative study between subepithelial connective tissue graft and guided tissue regeneration. $J$ Periodontol 2000;71:1441-1447.

32. Tatakis DN, Trombelli L. Gingival recession treatment: Guided tissue regeneration with bioabsorbable membrane versus connective tissue graft. J Periodontol 2000;71:299-307.

33. Rahmani ME, Lades MA. Comparative clinical evaluation of acellular dermal matrix allograft and connective tissue graft for the treatment of gingival recession. $J$ Contemp Dent Pract 2006;7:63-70.

34. Lee YM, Kim JY, Seol YJ, et al. A 3-year longitudinal evaluation of subpedicle free connective tissue graft for gingival recession coverage. J Periodontol 2002; 73:1412-1418.

35. Harris RJ. Root coverage with connective tissue grafts: An evaluation of short- and long-term results. J Periodontol 2002;73:1054-1059.

36. Müller HP, Eger T, Schorb A. Gingival dimensions after root coverage with free connective tissue grafts. J Clin Periodontol 1998;25:424-430.

37. Orsini M, Orsini G, Benlloch D, Aranda JJ, Lázaro P, Sanz M. Esthetic and dimensional evaluation of free connective tissue grafts in prosthetically treated patients: A 1-year clinical study. J Periodontol 2004; 75:470-477.

38. Edel A. The use of a free connective tissue graft to increase the width of attached gingiva. Oral Surg Oral Med Oral Pathol 1975;39:341-346.

39. Huang LH, Neiva RE, Wang HL. Factors affecting the outcomes of coronally advanced flap root coverage procedure. J Periodontol 2005;76:1729-1734. 
40. Baldi C, Pini-Prato G, Pagliaro U, et al. Coronally advanced flap procedure for root coverage. Is flap thickness a relevant predictor to achieve root coverage? A 19-case series. J Periodontol 1999;70:1077-1084.

41. Hwang D, Wang HL. Flap thickness as a predictor of root coverage: A systematic review. J Periodontol 2006;77:1625-1634.
Correspondence: Dr. Hom-Lay Wang, Department of Periodontics and Oral Medicine, School of Dentistry, University of Michigan, 1011 N. University, Ann Arbor, MI 481091078. Fax: 734/936-0374; e-mail: homlay@umich.edu.

Submitted December 24, 2008; accepted for publication February 16, 2009. 